\title{
Selected miscellaneous ovarian lesions: small cell carcinomas, mesothelial lesions, mesenchymal and mixed neoplasms, and non-neoplastic lesions
}

\author{
Philip B Clement \\ Department of Pathology of the Vancouver General Hospital and the University of British Columbia, BC, \\ Canada
}

\begin{abstract}
This contribution will cover a variety of uncommon tumors and tumor-like lesions of the ovary that can be associated with a myriad of diagnostic problems for the pathologist. A few of these lesions are not specific to the ovary and may be more common in the uterus or even extraovarian sites, but the mere knowledge that they also occasionally occur in, or involve, the ovary will facilitate their recognition by the pathologist. In contrast, the entity considered first, the highly malignant small cell carcinoma of hypercalcemic type, is an enigmatic tumor unique to the ovary.
\end{abstract}

Modern Pathology (2005) 18, S113-S129. doi:10.1038/modpathol.3800313

Keywords: ovary; small cell carcinoma; mesothelial lesions; smooth muscle tumors; myxoma; adenosarcoma; endometriosis

\section{Small cell carcinomas}

Small Cell Carcinoma, Hypercalcemic Type

\section{Background}

This tumor was recognized by Dr Robert E Scully in the mid-1970s when he encountered a series of ovarian tumors with a triad of findings that suggested a distinct entity: (1) occurrence in the ovary of an undifferentiated carcinoma composed of small cells with scanty cytoplasm that contrasted with the usual undifferentiated ovarian carcinoma composed of large cells with moderate to abundant cytoplasm; (2) occurrence in young patients; and (3) an association with hypercalcemia that reverted to normal after removal of the tumor and returned with its recurrence. The tumor was first illustrated and described in detail in 1979 in Dr Scully's first fascicle on ovarian tumors. ${ }^{1} \mathrm{~A}$ small series was then described in the literature in $1982^{2}$ and that resulted in a wider appreciation of this uncommon but not exceedingly rare tumor. Many additional cases were seen over the ensuing years, culminating in a

Correspondence: Dr PB Clement, MD, Department of Pathology, Vancouver General Hospital, 910 West 10th Avenue, Vancouver, B.C. Canada V5Z 4E3.

E-mail: pclement@vanhosp.bc.ca

Received and accepted 30 August 2004 report of 150 cases in $1994 .^{3}$ That study and others confirmed the initial experience and indicated that this tumor is the most common type of undifferentiated carcinoma of the ovary in women under the age of 40. As with many lesions, however, increased experience uncovered nuances of morphology and a better sense of the frequency of a variety of unusual features.

\section{Clinical features}

The patients have ranged in age from 7 months to 46 years, but there is a striking peak frequency in the second half of the second and third decade of life (mean age, 24 years). ${ }^{3,4}$ The diagnosis should be made with great caution in anyone over the age of 45 years. Rarely, the tumors are familial and possibly heritable, as exemplified by its occurrence in three sisters, a mother and daughter, and two first cousins. ${ }^{3,5,6}$ The tumors in these familial cases are more often bilateral than in these tumors in general, in which the frequency of bilaterality is only $1 \% .^{3}$

In the largest series, ${ }^{3} 62 \%$ of the patients in whom the serum calcium level was known had hypercalcemia. This is the most common ovarian tumor associated with hypercalcemia, accounting for $\sim 60 \%$ of such cases, and it is the only human cancer that is associated in the majority of cases with paraendocrine hypercalcemia. Thus, hypercalcemia in a 
young woman with an adnexal mass should suggest the diagnosis of hypercalcemic small cell carcinoma. It should be remembered, however, that the dysgerminoma, a more common neoplasm that occurs in the same age group, is also occasionally associated with hypercalcemia. ${ }^{7}$ This association is particularly relevant because these two neoplasms are occasionally confused on microscopic examination, as discussed later. The serum calcium can also be used to monitor the course of the disease and the response to therapy. Matias-Guiu et $a l^{8}$ found immunoreactivity for parathyroid-related polypeptide protein (PTHrp) in five of seven tumors; the serum calcium levels were elevated in two of the cases, were normal in two, and unknown in one. Interestingly, the two PTHrp-negative tumors were associated with hypercalcemia. This lack of correlation between PTHrp immunoreactivity and serum calcium levels is consistent with the fact that immunostaining is dependent on the peptide content of cells rather than their capability of hormone production and/or release. ${ }^{8}$ It should also be noted that the presence of PTHrp in small cell carcinomas does not necessarily prove that the PTHrp is responsible for the hypercalcemia in these patients as PTHrp is widely distributed in normal tissues and neoplasms. ${ }^{9}$

\section{Pathologic features}

Gross examination usually reveals a large (mean diameter, $15 \mathrm{~cm}$ ), predominantly solid, creamcolored mass resembling an ovarian lymphoma or dysgerminoma (Figure 1). Rupture is present in at least $20 \%$ of the tumors. Areas of necrosis, hemorrhage, and cystic degeneration are common; rare neoplasms are predominantly cystic. The most common microscopic pattern is a sheet-like arrangement of small, closely packed epithelial cells (Figures 2 and 3); nests, cords, trabeculae, and individually disposed cells may also be seen. A helpful, but often very focal, finding in $80 \%$ of cases

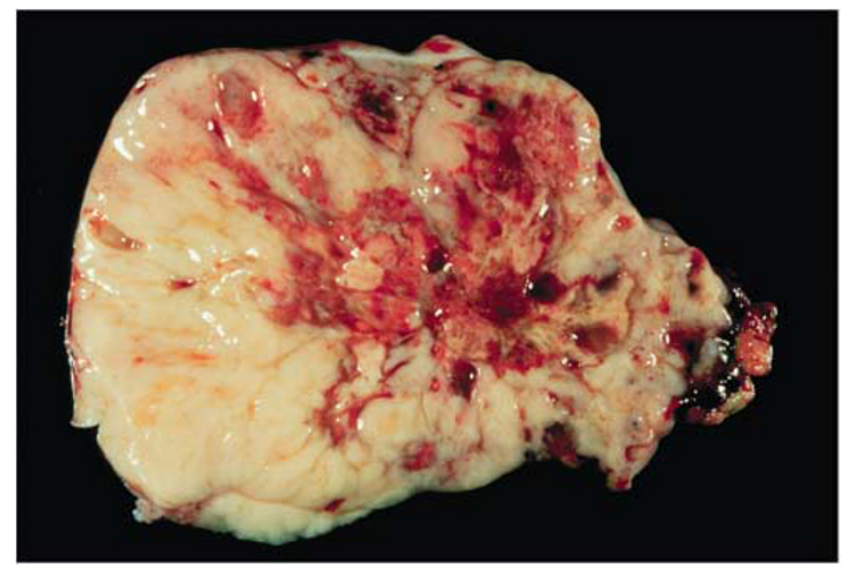

Figure 1 Hypercalcemic small cell carcinoma of ovary. Note fleshy white sectioned surface with areas of hemorrhage.

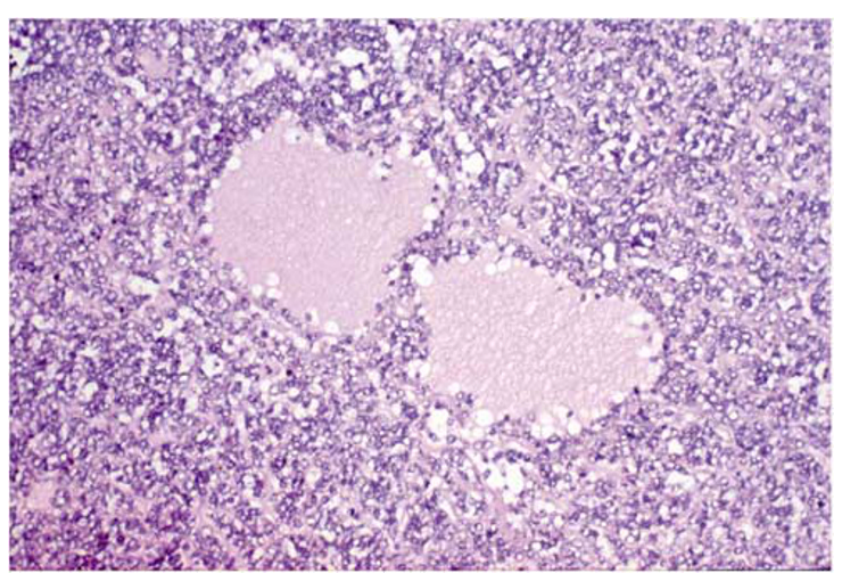

Figure 2 Hypercalcemic small cell carcinoma of ovary. Note follicle-like spaces.

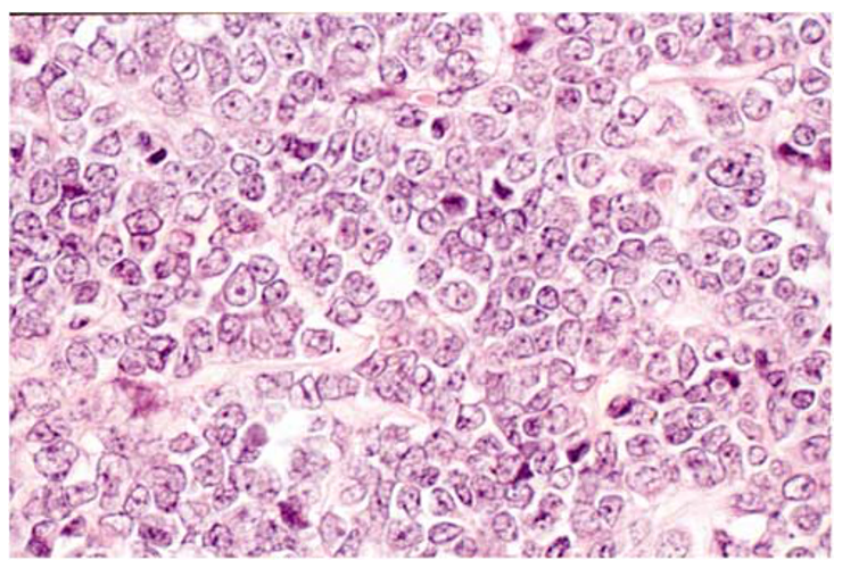

Figure 3 Hypercalcemic small cell carcinoma of ovary.

is variably sized follicles that contain eosinophilic fluid or are empty (Figure 2); rarely they contain basophilic fluid. The typical small rounded tumor cells are rather monomorphic and usually have scanty cytoplasm, small hyperchromatic nuclei, and single small nucleoli; mitotic figures are frequent (Figure 3).

Differences from the usual patterns just described can focally or extensively alter the appearance of the tumor, resulting in problems in differential diagnosis, especially if typical foci are not prominent. The most common of these findings, present in about half the tumors, is a component of large cells that usually represents a minor to moderate component of the tumor, but rarely can be the predominant or even exclusive component, leading to use of the descriptor 'large cell variant'. ${ }^{3}$ The large cells have moderate to abundant eosinophilic cytoplasm that can be dense and appear globular, with eccentric displacement of the nucleus (Figure 4). The large cells have larger, paler, more vesicular nuclei with more prominent nucleoli than do the small cells. Another potentially confusing finding is the presence of usually inconspicuous foci of mucinous 




Figure 4 Hypercalcemic small cell carcinoma showing a component of large cells with eosinophilic cytoplasm. Some of the cells have an eccentric nucleus resulting in a rhabdoid appearance.

epithelium in approximately $10 \%$ of the tumors. In such cases, glands or cysts are lined by benign to atypical appearing mucinous epithelium, and even signet-ring cells may be present. Other uncommon findings include foci of spindled tumor cells and rarely tumor cells with clear cytoplasm. ${ }^{3}$ The stroma of the tumor is typically inconspicuous with a nonspecific fibrous appearance, but is occasionally prominent and may be edematous, myxoid (particularly in areas with large cells), or, rarely, hyalinized. Vascular invasion at the periphery of the tumors is common.

Overall, $90 \%$ of tumors are immunoreactive for one or more cytokeratins, most consistently for CAM5.2 and CK7; staining for EMA is present in $30 \%$ of the tumors. ${ }^{3,10}$ Over half the tumors are immunoreactive for vimentin and neuron-specific enolase, and a sizable minority stain for chromogranin A. ${ }^{3,10}$ PRTrp-immunoreactivity has been detailed above. Immunoreactivity for p53 was documented in $80 \%$ of tumors in one study, supporting the presence of p53 mutations in these tumors. ${ }^{11}$ Idei et $a l^{12}$ performed genetic analysis of one tumor and revealed a K-ras codon12 point mutation, a finding regarded as one of the characteristics of tumors of epithelial origin.

Ultrastructural examination has shown that the tumor cells are of epithelial type, with cell junctions (desmosomes, tight junctions) and partial investment by basal lamina. ${ }^{13-15}$ The most consistent and prominent finding is abundant dilated rough endoplastic reticulum resulting in the formation of large vesicles filled with homogeneous granular material of variable density. ${ }^{14,15}$ Microfilaments are present in half the tumors and are particularly prominent in the large tumor cells in which they may form paranuclear whorls. ${ }^{14}$ Dense core granules have not been found in most studies (see Histogenesis). ${ }^{14,15}$ Flow cytometry on paraffin-embedded material has shown that the tumor cells are diploid. ${ }^{16}$
Differential diagnosis

The small cell carcinoma is most commonly misinterpreted as a granulosa cell tumor (GCT) of either the adult (AGCT) or juvenile type (JGCT). AGCTs have cells with pale grooved nuclei and lack the highly malignant nuclear features and the high mitotic rate of the small cell carcinoma. JGCTs lack the small cells that are usually present, at least focally, in small cell carcinomas with a component of large cells. Moreover, JGCTs are often associated with a theca cell component, a finding absent in small cell carcinomas, and have a more orderly architecture. Enigmatically, large pleomorphic nuclei with bizarre forms are actually more common in the JGCTs, the less malignant of the two tumors. Finally, in contrast to small cell carcinomas, both types of GCTs are typically immunoreactive for inhibin, although negativity for inhibin does not exclude a GCT as we have seen otherwise typical examples that are inhibin negative.

Small cell carcinoma can also be confused with malignant lymphoma, particularly when the former has a diffuse pattern. The much more common presence of epithelial growth patterns, including follicle-like structures in the small cell carcinoma and the differing clinical, cytological, immunohistochemical, and ultrastructural features of the two tumors enable one to distinguish them. The small cell carcinoma can occasionally be misinterpreted as other small cell malignant tumors that can involve the ovary such as primitive neuroectodermal tumors, primary or metastatic malignant melanoma, metastatic alveolar rhabdomyosarcoma, and desmoplastic small round cell tumor, but a variety of clinical and pathological features generally facilitate these differential diagnoses. ${ }^{4,17}$ The differential diagnosis also includes small cell carcinoma of pulmonary type that rarely occurs in the ovary as a primary tumor (see below) or is metastatic from another site.

As already noted, occasionally small cell carcinoma is misdiagnosed as a dysgerminoma, a tumor with a vastly different prognosis. The two tumors occur in a similar age range, can both be associated with hypercalcemia (albeit rarely in dysgerminomas), and can have a similar gross appearance. Misdiagnosis of a small cell carcinoma as a dysgerminoma occurs when the former has a nested pattern and clear cells. However, the typical small cells, the follicles, and the absence of the characteristic lymphoid infiltrate of the dysgerminoma facilitate the correct diagnosis. The typical angulated nuclear membranes of dysgerminoma are not a feature of the small cell carcinoma. If necessary, the typical immunostaining of dysgerminoma will aid in resolving the problem. It should be mentioned that dysgerminoma may show various changes such as degenerative spaces that should not be misconstrued as follicles, a finding that could lead to the converse error of misdiagnosing a dysgerminoma as a small cell carcinoma. 
Finally, the small cell carcinoma, particularly the large cell variant, may be misdiagnosed as undifferentiated carcinoma, not otherwise specified. This misdiagnosis may not necessarily adversely affect patient care or survival. The diagnosis of the large cell variant of small cell carcinoma should always be considered in a young patient if an undifferentiated carcinoma is suggested, and a diligent search for typical foci of small cell carcinoma, including the presence of follicles, performed.

\section{Behavior and prognosis}

These are highly aggressive tumors. At least half of them have spread beyond the ovary at the time of laparotomy, but this may be an underestimation as many of the patients were not optimally staged. ${ }^{3}$ Metastatic tumor occurs mostly within the pelvis and abdomen, but hematogenous spread also occurs. Only one-third of patients with stage Ia disease have disease-free follow-up periods and almost all patients with higher stage tumors die of disease, usually within 2 years. Effective treatment of patients with high-stage tumors or recurrent disease has not yet been achieved, although rare patients with high stage tumors have survived over 4 years after intensive chemotherapy, radiation therapy, or both. ${ }^{3,18,19}$ Potentially favorable prognostic features in stage Ia cases include an age $>30$ years, a normal preoperative calcium level, a tumor size $<10 \mathrm{~cm}$, an absence of large cells, an operation that included bilateral oophorectomy, and postoperative radiation therapy. ${ }^{3}$

\section{Histogenesis}

The histogenesis of this tumor remains a mystery. The possibilities include surface epithelial, sex cord-stromal, or germ cell origins, and yet transitions between the small cell carcinoma and tumors in these three categories have not been encountered. Features favoring a germ cell origin have been proposed, and yet evidence against a germ cell origin includes the observation that these tumors have never been encountered as a component of a mixed germ cell tumor in the ovary and in our opinion have never been encountered in the testis. A neuroendocrine origin was suggested in one study ${ }^{13}$ based on the presence of staining for neuron-specific enolase (NSE) and granules that were interpreted as of neurosecretory (dense core) type. However, the nonspecificity of NSE is now well recognized, and the neuroendocrine nature of the granules in this study was considered doubtful by other authors, ${ }^{20}$ and as noted above, dense core granules have been consistently absent in other studies. The current consensus is that these tumors are not neuroendocrine in type, ${ }^{14,15,20}$ and indeed, they have marked clinical and pathological differences from small cell carcinomas of neuroendocrine type of the ovary (see below). Evidence against a sex cord-stromal origin includes the uniform negativity of the tumors for inhibin, a marker that stains most ovarian sex cord- stromal tumors. The presence of mucinous epithelium in occasional tumors does not necessarily indicate a surface epithelial origin as mucinous epithelium can be encountered in ovarian tumors of diverse origins, and the age distribution of hypercalcemic small cell carcinomas is in striking contrast to that of surface epithelial tumors.

\section{Small Cell Carcinoma, Pulmonary Type and Large Cell Neuroendocrine Carcinoma}

Small cell carcinomas of pulmonary type arising in the ovary are so designated because of their similarity to small cell carcinomas of the lung and to segregate them from small cell carcinomas of hypercalcemic type because of important clinical and pathological differences from the latter. In the only series of these tumors, all the patients were in the reproductive or postmenopausal age groups (mean age, 59 years) and had a presentation similar to that of the usual ovarian cancer. ${ }^{21}$ One patient in that study had inappropriate secretion of antidiuretic hormone with recurrence of the tumor, and an example with the carcinoid syndrome and Cushing's syndrome was reported earlier. ${ }^{22}$ Almost half of the tumors in the above series were bilateral and almost two-thirds had extraovarian spread. The prognosis is poor with only one 5-year survival.

The tumors are usually large and solid, although some have had a minor cystic component. Microscopic examination shows the well-known features of this tumor in the lung. Most of the tumors are adjacent to, or intermingled with, a well-differentiated surface epithelial component that is usually an endometrioid carcinoma (Figure 5) or Brenner tumor, but in one case, mucinous cysts and glands were lined by atypical epithelium, and in another, foci of squamous epithelium were present. In one case, ${ }^{23}$ a small cell carcinoma arose from an ovarian teratoma indicated a possible neuroendocrine origin

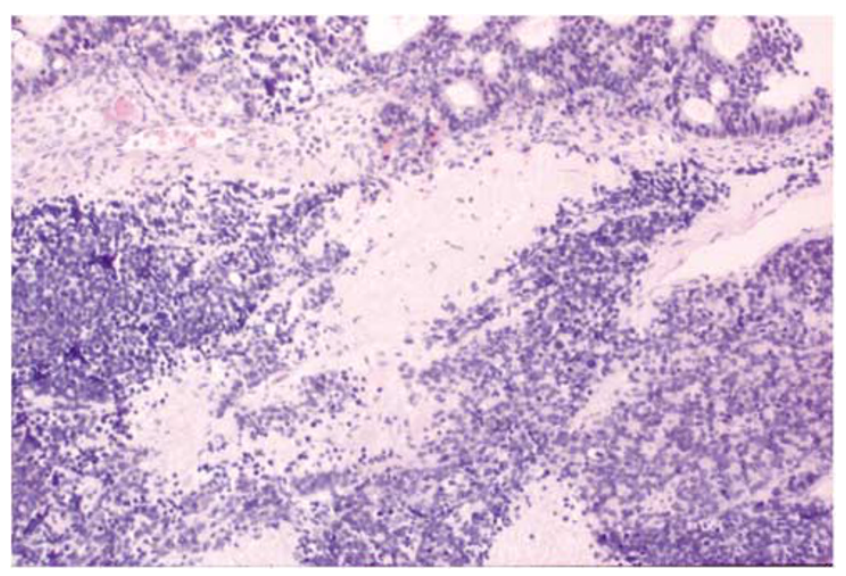

Figure 5 Small cell carcinoma of ovary of pulmonic type. Note admixed component of well-differentiated endometrioid carcinoma. 
Table 1 Differences between small cell carcinomas of hypercalcemic and pulmonary types

\begin{tabular}{|c|c|c|}
\hline & Hypercalcemic & Pulmonary \\
\hline Age (years) & $\begin{array}{l}7 \mathrm{~m}-46 \text { years } \\
\text { (mean } 23 \text { years) }\end{array}$ & $\begin{array}{l}\text { 28-85 years } \\
\text { (mean } 59 \text { years) }\end{array}$ \\
\hline Hypercalcemia & $62 \%$ & Absent \\
\hline Bilaterality & $1 \%$ & $45 \%$ \\
\hline Follicle-like spaces & Usual & Rare \\
\hline $\begin{array}{l}\text { Large cells with abundant } \\
\text { cytoplasm }\end{array}$ & $50 \%$ & Rare \\
\hline Nuclear chromatin & Clumped & Dispersed \\
\hline Nucleoli & Single, uniform & $\begin{array}{l}\text { Usually } \\
\text { inconspicuous }\end{array}$ \\
\hline $\begin{array}{l}\text { Endometrioid/Brenner } \\
\text { component }\end{array}$ & Absent & $>50 \%$ \\
\hline Ploidy & Diploid & Aneuploid \\
\hline $\begin{array}{l}\text { Epithelial membrane } \\
\text { antigen+ }\end{array}$ & $33 \%$ & Usually absent \\
\hline Vimentin+ & $50 \%$ & Usually absent \\
\hline $\begin{array}{l}\text { Prominent rough } \\
\text { endoplasmic reticulum }\end{array}$ & Present & Usually absent \\
\hline
\end{tabular}

in that case, but most neoplasms likely represent aberrant differentiation of a surface epithelial tumor.

These carcinomas contain argyrophil granules in a minority of cases. The majority are immunoreactive for keratin and neuron-specific enolase; less commonly, there is staining for epithelial membrane antigen, chromogranin, and Leu-7, but not vimentin. As with their pulmonary counterparts, they are usually chromogranin negative. Five of eight tumors tested were aneuploid and three were diploid. ${ }^{21}$

The features that facilitate distinction from small cell carcinomas of hypercalcemic type are listed in Table 1. Exclusion of a metastatic small cell carcinomas from the lung and rarely other sites is facilitated by the usual association of the primary tumors with a surface epithelial tumor and failure to clinically identify an extraovarian primary small cell carcinoma.

Recent observations indicate that, as in other organs, occasional carcinomas in the ovary have the features of the so-called large cell carcinomas of neuroendocrine type.$^{24}$ Like their small cell counterparts, these tumors typically occur in older women (mean age, 57 years) and are commonly associated with a surface epithelial tumor, which is usually endometrioid or mucinous. These tumors can also have growth patterns like those of the pulmonary type small cell carcinomas, but in contrast to the latter, they usually have trabecular or nested patterns and medium-sized to large tumor cells with moderate to abundant amounts of cytoplasm, coarser chromatin, and often a prominent nucleolus. The neoplastic cells are typically immunoreactive for chromogranin A.

\section{Mesothelial lesions}

Over the past two decades, it has become apparent that serous borderline tumors and carcinomas with an appearance identical to those arising in the ovary can arise from the peritoneum. In some of these cases, the surface of the ovaries is also involved, but the dominant disease is extraovarian. Less appreciated is the converse situation in which there is ovarian involvement by a mesothelial lesion. Lack of awareness of this phenomenon can result in diagnostic problems, particularly when the ovarian involvement dominates the clinical picture. This section will also include the intra-abdominal desmoplastic small round cell tumor, a tumor that has not yet been proven to be of mesothelial origin. However, its predilection for the peritoneum suggests such an origin.

\section{Mesothelial Hyperplasia}

Mesothelial hyperplasia can involve the ovary as a reaction to an ovarian lesion or as part of a more widespread peritoneal process in the absence of an ovarian neoplasm. ${ }^{25}$ In contrast to most cases of ovarian involvement by mesothelioma, mesothelial hyperplasia is usually an incidental microscopic finding restricted to the ovarian surface (Figures 6 and 7) or periovarian adhesions. Occasionally, however, the hyperplastic mesothelial cells can involve the walls of ovarian cystic tumors (Figure $8{ }^{25}$ or endometriotic cysts. ${ }^{26}$ In these cases, mesothelial cells in the form of tubules, nests, cords, or single cells within fibrous tissue can have an infiltrative pattern that can suggest an invasive tumor. A clue to the correct diagnosis in such cases is continuity and similarity of the cells to hyperplastic mesothelial cells on the serosal surface as well as the tendency for linear arrangements of the mesothelial cells. In difficult cases, the mesothelial nature of the cells can be confirmed with positivity for cytokeratin 5/6 and calretinin and negativity for epithelial markers such as Ber-EP4, B72.3, and Leu-M1. ${ }^{27}$

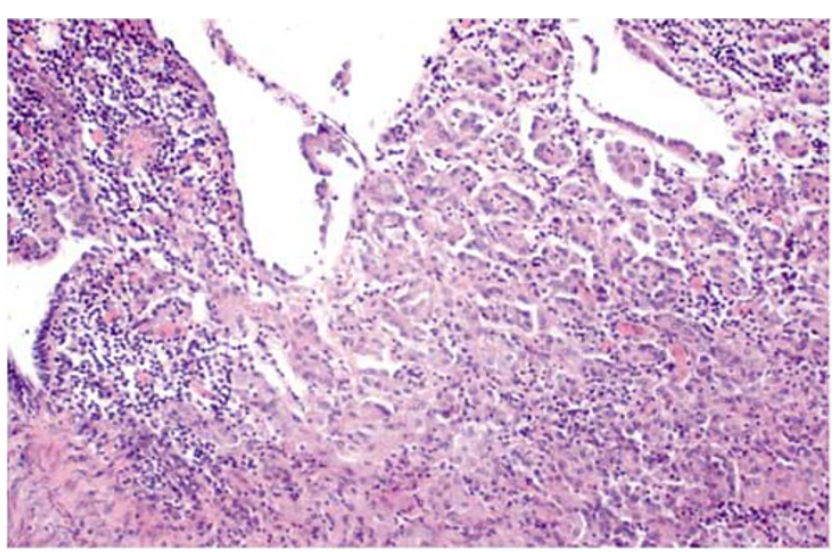

Figure 6 Mesothelial hyperplasia involving ovarian surface. The proliferation has a papillary pattern. 


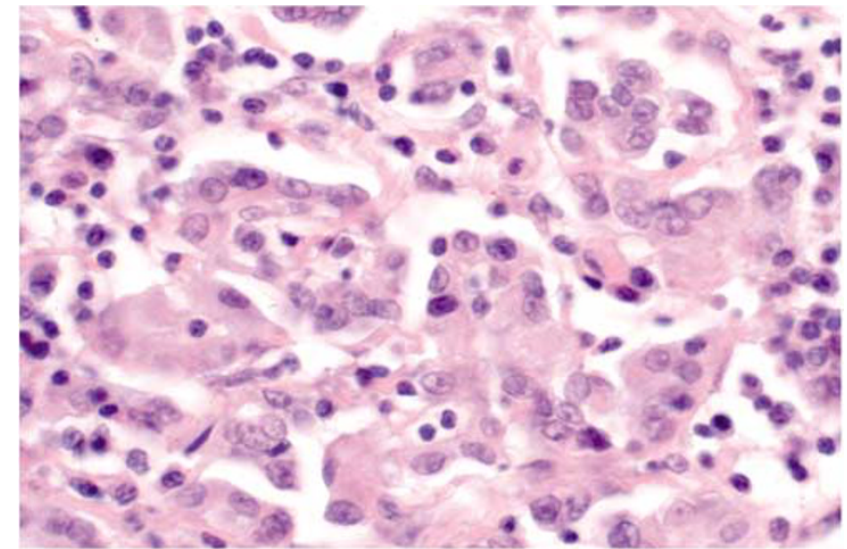

Figure 7 Mesothelial hyperplasia involving ovarian surface. The mesothelial cells have bland nuclear features and are admixed with lymphocytes.



Figure 8 Hyperplastic mesothelial cells within wall of ovarian serous borderline tumor. Some of the cells are arranged in cords. The mesothelial cells lie in spaces, an appearance that can be mistaken for lymphatic invasion.

\section{Adenomatoid Tumor}

Perhaps surprisingly, as it is the most common of all the mesothelial neoplasms of the female genital tract, adenomatoid tumors are only rarely encountered in the ovary. Only 11 well-documented ovarian examples have been reported, all in adults, and only two were symptomatic. ${ }^{28,29}$ Most of the tumors were hilar and $3 \mathrm{~cm}$ or less in diameter, but two were 6 and $8 \mathrm{~cm}$. They were typically solid but one was multicystic. Occasionally the tumors can be focally necrotic, like adenomatoid tumors elsewhere, ${ }^{30}$ a finding that may raise concern for a malignant tumor, especially if the characteristic patterns of an adenomatoid tumor are not prominent. For example, a recently encountered case of ovarian adenomatoid tumor had extensive necrosis and contained numerous signet-ring-like cells with eosinophilic secretions, findings that led to initial diagnostic uncertainty. In such unusual cases, the presence of more typical features elsewhere in the tumor, including the recently described 'thread-like

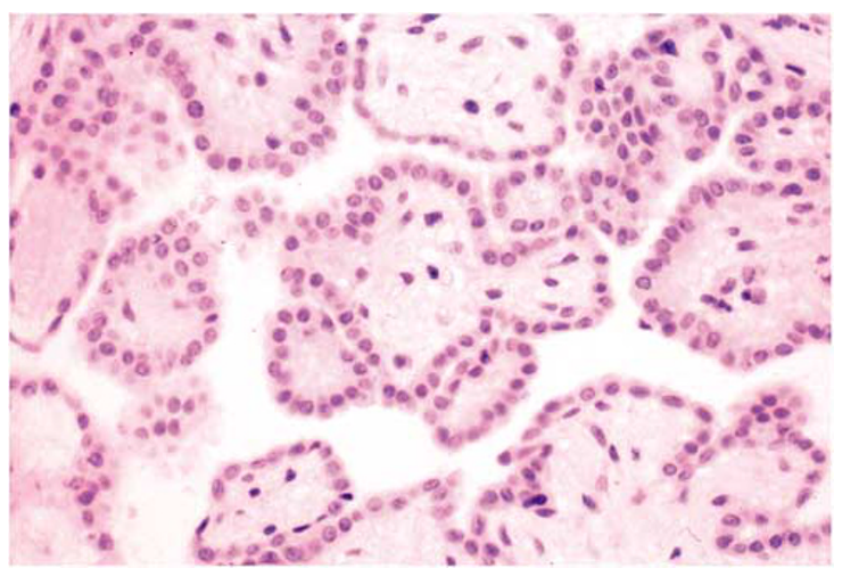

Figure 9 Well-differentiated papillary mesothelioma.

bridging strands' (due to apposition of attenuated cytoplasm between adjacent mesothelial cells), ${ }^{29}$ as well as immunostains to confirm the mesothelial nature of the tumor, can be helpful.

\section{Well-Differentiated Papillary Mesothelioma}

These tumors are much less common than their malignant counterparts (see below). In the largest study of well-differentiated papillary mesotheliomas of the peritoneum, ${ }^{31} 18$ of the 22 cases were in women, and four involved the ovaries. In that study, most of the tumors were multifocal, less than $2 \mathrm{~cm}$ in maximal dimension, and appeared as serosal nodules that were occasionally grossly papillary. The tumors are characterized by an orderly papillary pattern in which fibrous papillae are lined by a single layer of flattened to cuboidal mesothelial cells and benign nuclear features (Figure 9). Mitotic figures are rare or absent. Uncommon patterns include tubulopapillary, adenomatoid-like, branching cords, and solid sheets. When solitary, the tumors are benign. The behavior of multiple lesions is not as well defined. In some such cases, the tumor has been indolent, ${ }^{31}$ whereas in other cases, welldifferentiated tumor has been associated with typical malignant mesothelioma elsewhere in the peritoneum. ${ }^{32}$ Accordingly, when multiple tumors are present they should ideally be thoroughly sampled for microscopic examination in order to exclude malignant mesothelioma.

\section{Malignant Mesothelioma}

Ovarian involvement by malignant mesotheliomas is common when there is diffuse or multifocal involvement of the peritoneum, ${ }^{32,33}$ being present in 10 of 12 such cases in one study. ${ }^{32}$ The degree of ovarian involvement is usually similar to that on the extraovarian peritoneum, but rarely it is more striking, with a clinical presentation resembling that 
of an ovarian cancer. In one study of nine such cases, ${ }^{34}$ the tumor in two cases was confined to the ovary, suggesting a primary ovarian mesothelioma. In these cases of prominent or exclusive ovarian involvement, the tumor is particularly likely to be misinterpreted as a usual type of primary ovarian tumor, such as serous or clear cell carcinoma.

On gross examination, the ovarian involvement is commonly bilateral and can vary from multiple nodules involving the surface of the ovary, encasement of the ovary with minimal parenchymal involvement, or complete replacement of the ovary.

Most peritoneal malignant mesotheliomas, including those involving the ovaries, are of epithelial type (Figures 10-14). The diagnosis can usually be made or at least strongly suggested by examination of routinely stained slides, but because of some overlap in patterns (such as papillary patterns and slit-like spaces) with other tumors, the diagnosis can be challenging. The tumors exhibit, in order of frequency, tubular, papillary, or solid patterns that

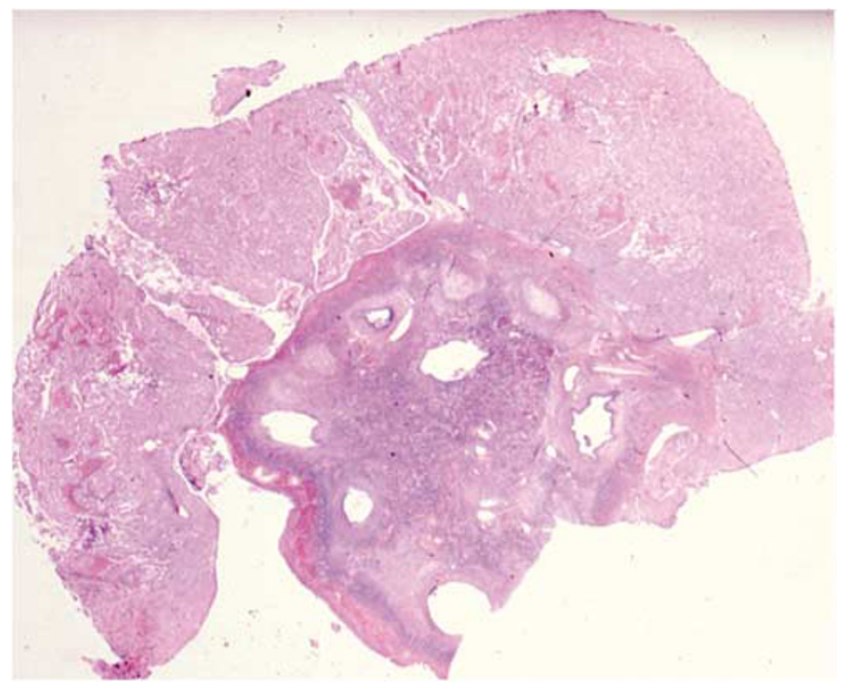

Figure 10 Malignant mesothelioma encasing an ovary.

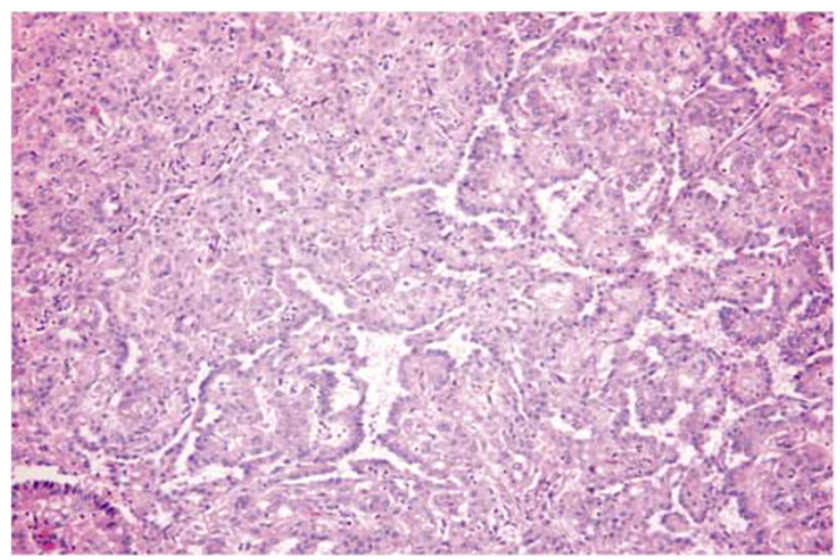

Figure 11 Malignant mesothelioma with tubulopapillary pattern. are commonly admixed (Figures 11-13). ${ }^{32-34}$ Tumors that are predominantly epithelial may merge with minor foci in which the cells are spindle-shaped. The cells lining the papillae are usually less

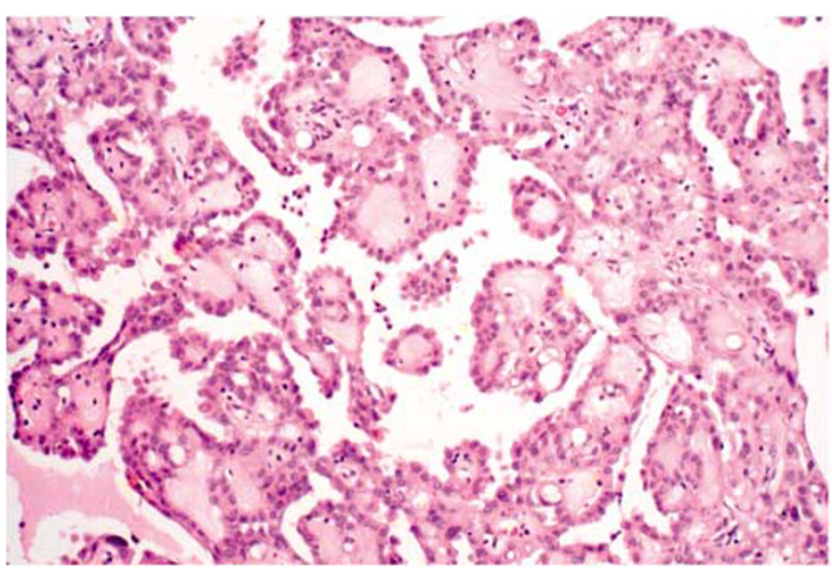

Figure 12 Malignant mesothelioma with papillary pattern. Many of the papillae have hyalinized cores.

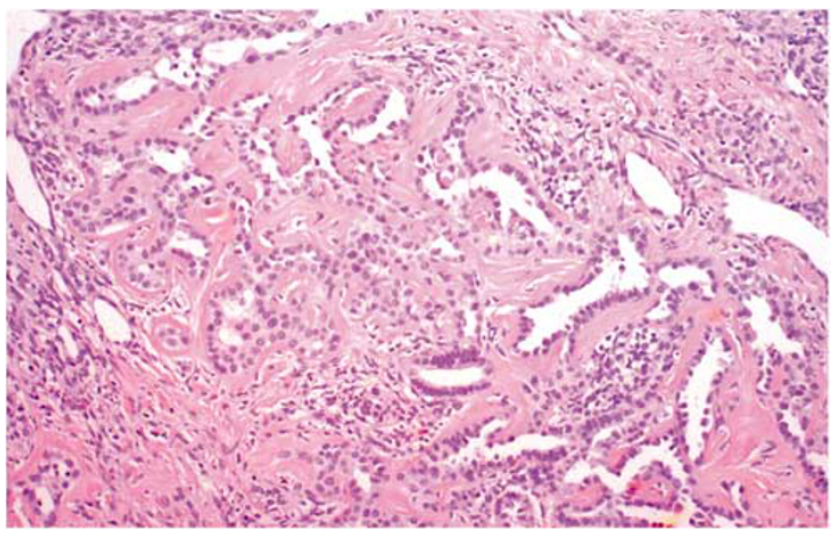

Figure 13 Malignant mesothelioma involving ovary. The tumor had a prominent tubular pattern that was focally somewhat retiform.



Figure 14 Malignant mesothelioma involving ovary. High-power view showing cuboidal cells with eosinophilic cytoplasm and moderately atypical nuclei. 
stratified and are less likely to form cellular buds than in papillary serous carcinomas. The neoplastic cells usually retain a resemblance to normal or hyperplastic mesothelial cells, being typically cuboidal with moderate amounts of eosinophilic cytoplasm (Figure 14). Cells lining spaces or papillae are often low columnar or flattened; occasional hobnail-type cells may also be present. Variably size cytoplasmic vacuoles are present to some extent in many tumors, and large cytoplasmic vacuoles can result in a signet-ring appearance. Most of the tumors exhibit only mild to moderate degrees of nuclear atypia (Figure 14) in contrast to the high-grade nuclear features of most serous carcinomas. Similarly, the tumors tend to have lower mitotic rates than in serous carcinomas. In the study of mesotheliomas with prominent ovarian involvement, mitotic figures were rare $(<1 / 10 \mathrm{HPFs})$ in six cases and 3-6 MFs/10HPFs in the other three cases. Additionally, the typical tight cellular clusters of well-differentiated serous carcinomas are not a feature of malignant mesotheliomas. Psammoma bodies are less common (present in approximately $20 \%$ of cases) and when present are rarely as numerous as they are in serous carcinomas. ${ }^{33}$ The stroma is usually fibrous and can vary from scanty to abundant; the fibrous cores of papillae are commonly hyalinized (Figure 12), a potential source of confusion with clear cell carcinomas that often have a similar feature. Rare tumors have a highly myxoid stroma. ${ }^{33}$ Some tumors have striking inflammatory infiltrates of foamy histiocytes and/or lymphocytes; the latter may include lymphoid nodules or follicles. Necrosis was present in approximately $15 \%$ of peritoneal mesotheliomas in one study, and in onethird of those cases it was prominent. ${ }^{33}$

Patterns and cell types that differ from the usual appearance can result in additional problems in differential diagnosis and possible confusion with primary ovarian tumors other than serous carcinomas. In at least some of these cases, however, the focal presence of the characteristic tubulopapillary pattern with tumor cells resembling mesothelial cells will facilitate the correct diagnosis. 'Deciduoid' mesotheliomas are most common in the peritoneum of women, and several such tumors have involved the ovaries. ${ }^{35,36}$ This pattern is characterized by a predominantly or exclusively sheet-like pattern of cells with abundant eosinophilic glassy cytoplasm (Figure 15). The prominent nucleoli, often brisk mitotic activity, and immunoreactivity of the tumor cells for cytokeratin exclude an ectopic decidual reaction. Deciduoid mesotheliomas also raise a broad differential with ovarian tumors of diverse types that are characterized by oxyphilic cells, tumors that have been covered in detail elsewhere. ${ }^{17}$ Rare peritoneal mesotheliomas can have insular, trabecular, tubular, and retiform patterns, as well as cells with nuclear grooves, potentially mimicking a sex cord-stromal tumor. ${ }^{33}$ Biphasic and purely sarcomatous peritoneal mesotheliomas are much

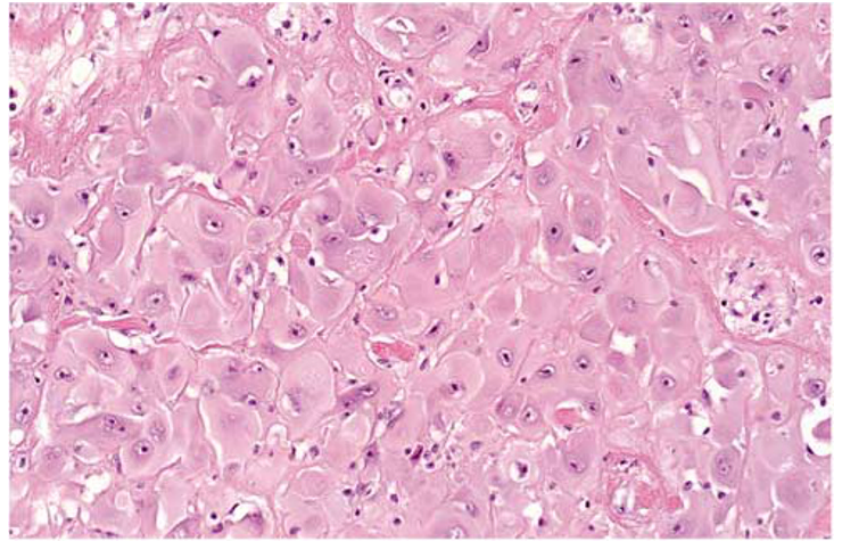

Figure 15 Malignant mesothelioma with deciduoid pattern.

rarer than these subtypes in the pleura. Several biphasic mesotheliomas have had prominent ovarian involvement, ${ }^{34}$ tumors that potentially may be confused with a primary ovarian malignant mesodermal mixed tumor (MMMT). The epithelial components of biphasic mesotheliomas usually resemble pure epithelial mesotheliomas, contrasting with the high-grade Mullerian-type carcinomatous component of the typical MMMT. Heterologous sarcomatous elements can occur in both biphasic mesotheliomas and MMMTs, and thus their presence is not diagnostically helpful. Rare peritoneal mesotheliomas, one of which involved the ovaries, ${ }^{37}$ have abundant foamy cytoplasm due to lipid within the tumor cells. Solid patterns in such tumors with ovarian involvement could lead to possible confusion with other lipid-rich ovarian tumors such as steroid cell tumors. Minor foci of cells with clear cytoplasm are common in peritoneal mesotheliomas, and rarely they can be a prominent cell type. ${ }^{33}$ The presence of clear cells, especially if accompanied by hobnail cells and hyalinized papillae (as noted above), could raise a differential diagnosis with a clear cell carcinoma. In such cases, the absence of the typical tubulocystic pattern of clear cell carcinoma, relative blandness of nuclear features in mesotheliomas compared to clear cell carcinomas, and the different immunohistochemical features of the two tumors will resolve the diagnostic problem.

The characteristic appearance on routinely stained slides and awareness that malignant mesotheliomas can involve the ovaries facilitate their recognition. Additionally, an absence of neutral mucin and an immunoprofile supporting a mesothelial nature of the cells can help confirm the diagnosis, especially in difficult cases. Mesotheliomas usually lack immunoreactivity for a variety of 'epithelial' antigens, including B72.3, Leu-M1 (CD15), Ber-EP4, CEA, CA19-9, and S-100 protein. Of these, Ber-EP4, B72.3, Leu-M1 (CD15), MOC-31, and CA19-9 are the most useful in the differential with primary peritoneal serous carcinoma. ${ }^{38}$ Anti- 
gens that are usually present in epithelial mesotheliomas but not serous carcinomas are cytokeratin $5 / 6$, thrombomodulin, and calretinin. No single immunohistochemical stain, however, is diagnostic in this differential diagnosis, and the results of a panel of antibodies should be interpreted in conjunction with the routine and mucin stains.

\section{Intra-Abdominal Desmoplastic Small Round Cell Tumor}

As noted earlier, these tumors (DSRCTs), which are of uncertain histogenesis but may prove to be of mesothelial origin ('mesothelioblastoma'), ${ }^{39-44}$ can present as 'ovarian cancer' and are therefore appropriately discussed here. DSRCTs, which overall have a strong male predilection (M:F ratio 4:1), are most common in adolescents and young adults (range 376 [mean, 21] years) who usually have abdominal distension, pain, and a palpable abdominal or pelvic mass, sometimes in association with ascites. Some patients have had an elevated serum level of CA 125 or neuron-specific enolase. DSRCTs exhibit a unique reciprocal translocation $[\mathrm{t}(11 ; 22)(\mathrm{p} 13 ; \mathrm{q} 12)]$ that results in the EWS/WT1 chimeric transcript, the presence of which is essentially diagnostic for DSRCT. ${ }^{45}$ The EWS/ERG fusion gene characteristic of Ewing's sarcoma/peripheral neuroectodermal tumors has been found in rare otherwise similar DSRCTs,${ }^{46}$ suggesting some overlap between the two groups of tumors. Laparotomy typically discloses variably sized but usually large, intra-abdominal masses associated with smaller peritoneal 'implants' of similar appearance. DSRCTs are highly aggressive; over $90 \%$ of patients die from tumor.

On gross examination, the tumors, which may be huge, have smooth or bosselated outer surfaces and firm to hard, gray-white, focally myxoid and necrotic sectioned-surfaces. Direct invasion of intra-abdominal or pelvic viscera may occur. Microscopic examination reveals sharply circumscribed aggregates of small cells delimited by a desmoplastic stroma. The aggregates vary from tiny clusters (or even single cells) to rounded or irregularly shaped islands with sometimes a vaguely squamoid or basaloid appearance. Other common features include rounded rosette-like or gland-like spaces, peripheral palisading of basaloid cells in some of the nests, and central necrosis with or without calcification. The tumor cells are typically uniform with scanty cytoplasm and indistinct cell borders, although tumor cells with eosinophilic cytoplasmic 'inclusions' and an eccentric nucleus, resulting in a rhabdoid appearance, are frequently also present. Small- to medium-sized, round, oval, or spindleshaped hyperchromatic nuclei have clumped chromatin and nucleoli that are usually inapparent. Mitotic figures and single necrotic cells are numerous. Architectural features noted in a minority of cases, which can occasionally predominate and lead to diagnostic problems, include tubules, glands (sometimes with luminal mucin), cysts, papillae, anastomosing trabeculae, cords of cells mimicking lobular breast carcinoma, adenoid cystic-like foci, and only a sparse desmoplastic stroma. ${ }^{42}$ Cytological features noted in a minority of cases, which can occasionally predominate, include spindle cells, cells with abundant eosinophilic or clear cytoplasm, signet-ring-like cells, and cells with marked nuclear pleomorphism. ${ }^{42}$ Invasion of vascular spaces, especially lymphatics, is a common feature. Lymph nodes are occasionally involved by tumor.

The usual immunoreactivity for epithelial (low molecular weight cytokeratins, EMA), neural/neuroendocrine (NSE, CD57/Leu-7), and muscle (desmin) markers, as well as vimentin, suggests divergent differentiation. Desmin and vimentin immunoreactivity is typically paranuclear and globular, and is particularly intense in the rhabdoid cells. ${ }^{40}$ Nuclear immunoreactivity for the C-terminal region of the Wilms' tumor protein (WT1) was also present in all 28 tumors tested in two studies, a finding that is useful in separating DSRCTs from Ewing sarcoma/PNET. ${ }^{47,48}$ DSRCTs are typically negative for HBA 71, the Ewing's sarcoma/PNET antigen. Ultrastructural variability suggests a range of differentiation. ${ }^{43}$ Cell junctions have varied from scant and primitive to more prominent ones including intermediate, desmosomal, and tight types. Paranuclear intermediate cytoplasmic filaments and basal lamina surrounding the nests of tumor have been prominent features in most of the cases.

\section{Mesenchymal and mixed neoplasms}

\section{Smooth Muscle Tumors}

It should be noted first that paraovarian leiomyomas are more common than ovarian leiomyomas and some tumors submitted as 'ovarian' may, on review of operative findings and/or careful gross examination, be shown not to originate in the ovary. Ovarian leiomyomas occur predominantly in premenopausal adult women and have no distinctive clinical features. ${ }^{49-52}$ Rare associated findings have included Meigs' syndrome, adjacent hilus cell hyperplasia with elevated plasma testosterone and virilization, diffuse peritoneal leiomyomatosis, and intravenous leiomyomatosis in which the ovarian tumor was the probable source of the intravenous tumor.

The tumors are usually $<5 \mathrm{~cm}$ in diameter but are occasionally massive. They usually resemble their uterine counterparts grossly and microscopically, including the occurrence of leiomyoma variants, such as hydropic, myxoid, cellular, with bizarre nuclei (Figure 16), and epithelioid. ${ }^{52}$

The differential diagnosis includes the much more common ovarian fibroma. These tumors are composed of fibroblastic cells, often in a storiform pattern, with abundant intercellular collagen. The differential diagnosis of ovarian leiomyomas with 


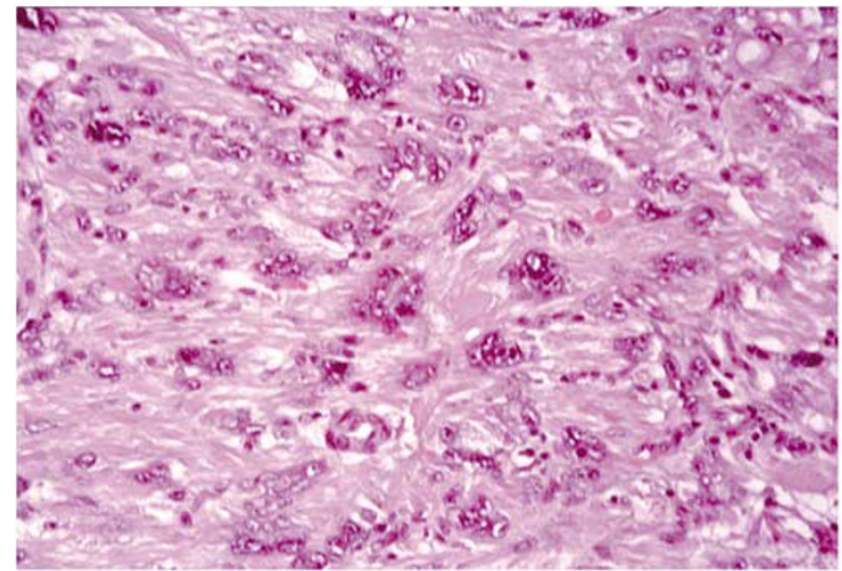

Figure 16 Ovarian leiomyoma with bizarre nuclei. Mitotic figures were rare.

unusual features may be with a wide variety of ovarian tumors including sex cord-stromal tumors if cords of cells are present as in some leiomyomas with hydropic change or hyalinization. Establishing the correct diagnosis requires an index of suspicion, and appreciation of foci of more typical smooth muscle differentiation that may be present in some tumors, and immunostaining for desmin and other markers.

A recent large study ${ }^{52}$ determined that most ovarian leiomyosarcomas, including two that were myxoid, could be identified with criteria similar to those used for their uterine counterparts. Most of the leiomyosarcomas were readily diagnosed by the presence of at least two of the following: moderate or severe cytologic atypia, a mitotic rate of $\geq 10$ mitotic figures per 10 high-power fields (MFs/10 HPFs), and tumor cell necrosis. Some cytologically atypical tumors had only 5-9 MFs/10 HPFs and no tumor cell necrosis; $60 \%$ of this subgroup were clinically malignant, supporting a diagnosis of leiomyosarcoma. Follow-up in 21 patients revealed recurrent disease in $71 \%$ of them at a mean of 19 months, and $62 \%$ died of their disease at a mean of 24 months. Four additional tumors were judged of uncertain malignant potential; two that were stage II both recurred in the pelvis. One case of ovarian intravenous leiomyomatosis had a benign outcome at 42 months, as did one case of ovarian leiomyoma with peritoneal leiomyomatosis at 180 months. The main tumors in the differential diagnosis of ovarian leiomyosarcomas are fibrosarcomas, spindle cell carcinomas, and metastatic gastrointestinal stromal tumors.

\section{Myxoma}

These rare tumors have occurred in patients of reproductive age who had an asymptomatic unilateral adnexal mass. ${ }^{53-56}$ The histogenesis of these tumors is not known with certainty, but the presence of myxoid areas in tumors in the thecoma-fibroma group and sclerosing stromal tumors suggest that at least some myxomas are of ovarian stromal origin. Indeed, Costa et al ${ }^{53}$ have suggested that ovarian myxomas may be at one end of the spectrum of differentiation in the thecoma-fibroma group of tumors in which no residual stromal tumor is detectable. On the other hand, the morphology of myxomas is different from that seen in tumors unquestionably in the fibroma-thecoma group, suggesting no relationship to the latter. The tumors have been clinically benign on follow-up except one case that recurred 19 years postoperatively. ${ }^{56}$

The mean diameter of the tumors is $11 \mathrm{~cm}$ and they typically have soft sectioned surfaces, often with focal cystic degeneration. On microscopic examination, the tumors have abundant, pale blue to pink intercellular matrix (the degree of eosinophilia reflecting the amount of collagen present) and a prominent plexus of small blood vessels. The intercellular material stains with colloidal iron and alcian blue and is sensitive to pretreatment with hyaluronidase. The bland tumor cells vary from spindle-shaped to stellate with long tapering cytoplasmic processes. Ultrastructural and immunohistochemical findings (immunoreactivity for vimentin, smooth muscle actin, and occasionally desmin) indicate that the cells are myofibroblasts.

The most important differential of ovarian myxomas is with low-grade sarcomas with myxoid features. Features favoring myxoma include bland cytologic features and very rare to absent mitotic figures. The diagnosis of myxoma should be made with caution in the presence of extraovarian tumor, even slight cytologic atypia, or occasional mitoses. The typical features of a myxoma including its alcianophilic matrix and the absence of follicles and their derivatives within the tumor facilitate the differential diagnosis with massive edema.

\section{Mesodermal Adenosarcomas}

These tumors ${ }^{57}$ are much less common that their uterine counterparts, ${ }^{58}$ and the features of the tumors in the two sites differ in some important respects (Table 2). The ovarian tumors occur in women over a wide age range (30-84 years of age) but have a peak frequency in the fifth decade, compared to the eighth decade for the uterine tumors. The clinical presentation of the ovarian tumors is similar to that of ovarian tumors in general. Approximately one-third of the ovarian tumors were associated with extraovarian spread, whereas almost all uterine adenosarcomas are stage I. Tumor rupture occurs at or before the operation in two-thirds of the ovarian tumors. The ovarian tumors are almost always unilateral and reach larger sizes than their uterine counterparts (mean dimension 14 vs $5 \mathrm{~cm}$ ). Most of the ovarian tumors are 
Table 2 Adenosarcomas of the ovary and uterus

\begin{tabular}{lcc}
\hline & Ovarian & Uterine \\
\hline Peak age & fifth decade & eighth decade \\
Stage >I & $35 \%$ & $<1 \%$ \\
Mean diameter (cm) & 14 & 5 \\
Grossly polypoid/papillary & rare & typical \\
Sarcomatous overgrowth & $30 \%$ & $8 \%{ }^{\mathrm{a}}$ \\
Sex cord-like elements & $15 \%$ & $7 \%$ \\
Heterologous elements & $12.5 \%$ & $25 \%$ \\
Recurrence & $77 \%$ & $25 \%$ \\
First recurrence <5 years ${ }^{\mathrm{b}}$ & $90 \%$ & $67 \%$ \\
Hematogenous spread & $20 \%$ & $2 \%$ \\
\end{tabular}

${ }^{\mathrm{a}}$ Based on ref. 58. Another study ${ }^{60}$ found a much higher frequency of sarcomatous overgrowth, but this was a Gynecology Oncology Group study in which a hysterectomy, bilateral adnexectomy, and pelvic lymph node sampling was a prerequisite for admission, probably limiting the inclusion of patients with small, low-stage, and low-grade tumors.

${ }^{b}$ First recurrence diagnosed within 5 years after initial treatment. Figures represent the proportion of the cases with recurrence, not the total number of cases in the study.



Figure 17 Mesodermal adenosarcoma of ovary, sectioned surface. Note sponge-like sectioned surface.

predominantly solid, but they often contain numerous small cysts (Figure 17). Grossly visible papillae or polypoid projections from the surface of the tumor or within cysts are much less common in the ovarian tumors than in the uterine tumors, in which this finding is typical. On microscopic examination, the ovarian tumors resemble the uterine tumors, being composed of an admixture of benign-appearing, but occasionally atypical, glands and a sarcomatous stroma that is usually low-grade (Figures 18 and 19). The latter typically exhibits periglandular condensation and intraglandular polypoid and/or papillary projections (Figure 18). The glands are most commonly of proliferative endometrioid type, but other types of Mullerian epithelia (tubal,



Figure 18 Mesodermal adenosarcoma of ovary. Note intraglandular polypoid projections of stromal component.

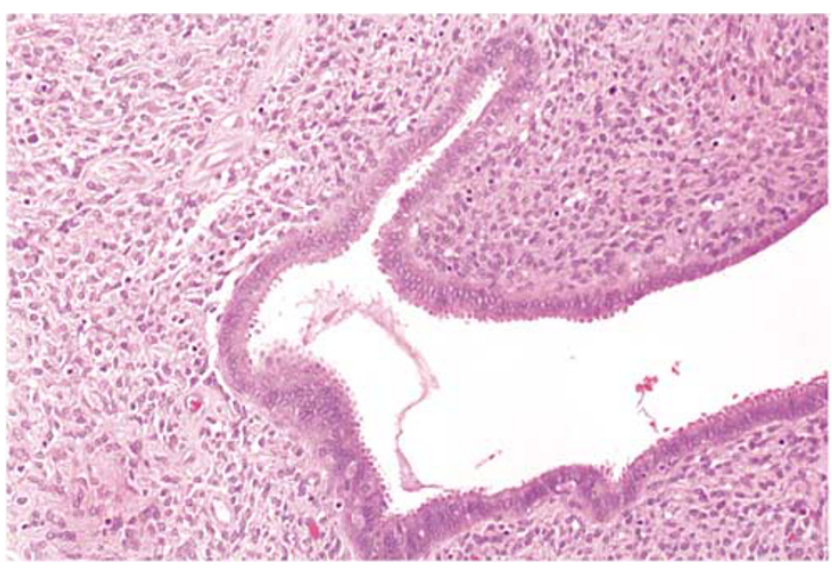

Figure 19 Mesodermal adenosarcoma of ovary. Note low-grade sarcomatous stroma cuffing a benign-appearing endometrioid gland.

squamous) are also commonly present. Cystic dilatation of the glands is common. The glands are usually uniformly distributed but in a minority of cases exhibit glandular crowding, complexity, or both. Mitotic figures are almost always identifiable (mean $4 \mathrm{MFs} / 10 \mathrm{HPFs}$ ), but in some tumors the mitotic counts are low $(<1 \mathrm{MF} / 10 \mathrm{HPFs})$. The stroma is fundamentally of endometrioid stromal type but the variable appearance of that neoplastic element may result in various unusual features. Prominent areas of stromal hyalinization and/or edema can result in paucicellular areas that have a deceptively benign appearance. The stromal cells may exhibit sex-cord-like formations, a finding that can be very confusing particularly if prominent. Sarcomatous overgrowth, which is more common in the ovarian than the uterine tumors ( 30 vs $8 \%$ ), is characterized by overgrowth of at least $25 \%$ of the adenosarcoma by a pure sarcoma, which is sometimes of a higher grade than the sarcomatous component of the associated adenosarcoma. Sexcord-like elements are more common in the ovarian 
tumors (15 vs 7\%), whereas heterologous elements are less common (12.5 vs $22 \%$ ).

Ovarian adenosarcomas are considerably more aggressive that their uterine counterparts, presumably because of the greater ease of peritoneal spread. In all, $77 \%$ of women with postoperative follow-up (compared to $26 \%$ of patients with uterine adenosarcomas) had recurrent tumor at 0.4-6.6 (mean, 2.6) years after operation. ${ }^{57}$ The recurrent tumor may be a pure sarcoma (low grade or high grade) or adenosarcoma (with or without sarcomatous overgrowth); $20 \%$ of those with recurrent tumor had blood-borne metastases. The 5-, 10-, and 15-year survival rates were 64,46 , and $30 \%$, respectively. An age $<53$ years, tumor rupture, a high-grade sarcomatous component, and high-grade sarcomatous overgrowth are all associated with an increased risk of recurrence or extraovarian spread.

The most important problem in differential diagnosis is underdiagnosis of ovarian adenosarcoma as a benign lesion, such as an adenofibroma, cystadenofibroma, florid endometriosis, or polypoid endometriosis. The presence of periglandular cuffs of cellular stroma and intraglandular papillae of cellular stroma strongly favor a diagnosis of adenosarcoma even if these findings are focal, especially when accompanied by atypia and/or mitotic activity of the stromal component. It should be noted, however, that occasional otherwise typical endometrioid cystadenofibromas may have a cellular stroma and occasional mitotic figures, but in such cases the other features of adenosarcoma are absent. Polypoid endometriosis has an appearance similar to that of endometrial polyps or endometrial hyperplasia. In a recent series of 24 cases of polypoid endometriosis, ${ }^{59}$ focal intraglandular stromal papillae were noted in two cases with focal periglandular stromal hypercellularity in one of them, but no stromal cell atypia was present in either case. The differential diagnosis of ovarian adenosarcoma also includes other tumors, particularly when unusual features are present. The presence of sex cord-like elements sometimes raises a diagnosis of a sex-cord-stromal tumor, but the presence of even rare glands and in some cases the endometrioid appearance of the stromal component are clues to the diagnosis of adenosarcoma. Adenosarcomas with extensive sarcomatous overgrowth can be confused with endometrioid stromal sarcoma, fibrosarcoma, or diffuse adult granulosa cell tumor. The most difficult of these is endometrioid stromal sarcoma (ESS). The cells comprising the areas of sarcomatous overgrowth, however, are usually more atypical and mitotically active than those of the usual ESS. Thorough sampling to exclude sometimes minor foci of adenosarcoma may be important when examining ovarian tumors having the features of ESS since an adenosarcoma has a poorer prognosis than an ESS. The presence of marked epithelial atypia and heterologous elements in an ovarian adenosarcoma may suggest a diagnosis of malignant mesodermal mixed tumor (MMMT). Severe epithelial atypia is present in less than $10 \%$ of ovarian adenosarcomas, and in these cases it is limited to scattered glands and is noninvasive, and is accompanied by a usually low-grade sarcomatous component. In contrast, MMMTs are typically composed of a high-grade sarcomatous component and an invasive high-grade carcinomatous component. The differential diagnosis of recurrent tumor can be a particular challenge as the typical biphasic growth pattern is often inconspicuous or absent. Knowledge of the history of an ovarian adenosarcoma and its known potential to recur as a pure sarcoma should make the diagnosis evident.

\section{Non-neoplastic lesions}

A number of non-neoplastic lesions of the ovary occur as a result of the hormonal milieu of pregnancy. Some of them can be confused with a neoplasm clinically, intraoperatively, or on pathological examination, potentially leading to overly aggressive treatment. Two of them, the pregnancy luteoma and hyperreactio luteinalis, are well known and will not be considered here as there is no new information pertaining to these lesions that can be added from what is available in standard texts. ${ }^{61}$ Several other recently described or re-emphasized non-neoplastic lesions unrelated to pregnancy are also discussed.

\section{Large Solitary Luteinized Follicle Cyst of Pregnancy and Puerperium}

This unusual lesion can result in problems in differential diagnosis, although the diagnosis is straightforward if the pathologist is familiar with its distinctive features. ${ }^{62}$ The cyst may cause abdominal swelling, but it is usually an incidental finding at cesarean section or on physical examination during the first postpartum visit. No endocrine disturbance has been reported.

The cysts are usually large (median diameter, $25 \mathrm{~cm}$ ), unilocular, thin-walled, and contain watery fluid. One to several layers of large luteinized granulosa and/or theca cells line the cyst and frequently form nests embedded in the fibrous wall of the cyst. The cells have abundant eosinophilic to, less often, vacuolated cytoplasm, vary considerably in size and shape, and exhibit focal marked nuclear pleomorphism and hyperchromasia with a degenerative appearance (Figure 20); mitotic figures are absent. All the patients have had an uneventful postoperative course.

The differential diagnosis is usually with a unilocular cystic granulosa cell tumor of adult or juvenile type. The presence of follicles or other epithelial formations in the lining or wall of the granulosa cell tumors is a helpful distinguishing feature. Additionally, the often striking degenerative 


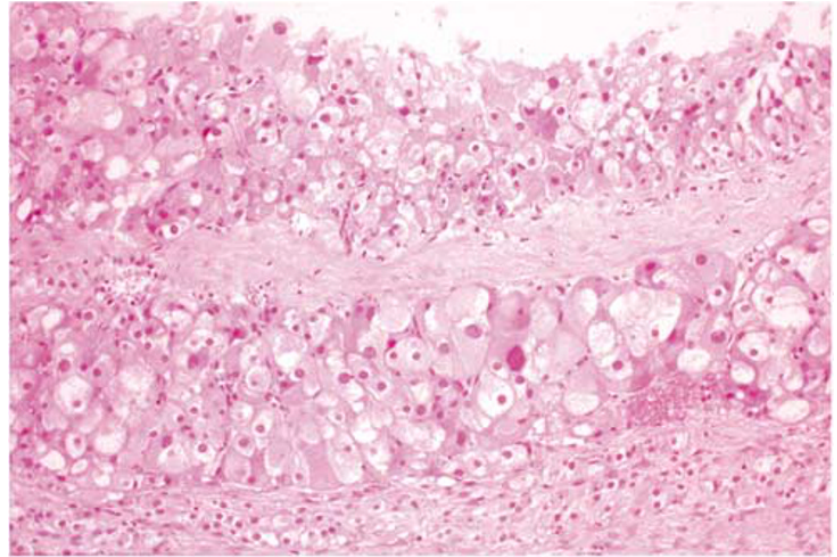

Figure 20 Large solitary luteinized follicle cyst of pregnancy. The luteinized cells have abundant eosinophilic or clear cytoplasm and focally atypical nuclei.

atypia encountered in the large luteinized follicle cysts is not a typical feature of unilocular granulosa cell tumors.

\section{Granulosa Cell Proliferations of Pregnancy}

These microscopic proliferations resemble miniature sex cord-stromal tumors, and although of no apparent clinical significance, they can be associated with diagnostic problems for the pathologist. ${ }^{63}$ The process has been encountered as an incidental finding in the ovaries of pregnant women, and rarely, nonpregnant women and newborns. The proliferations are usually multiple and lie within atretic follicles, which are typically enveloped by a thick layer of luteinized theca cells. The granulosa cells may be arranged in solid, insular, microfollicular, or trabecular patterns, and contain scanty cytoplasm and grooved nuclei (Figure 21). Rarely, the proliferating cells simulate a small Sertoli cell tumor, growing in a solid tubular pattern and containing moderate amounts of finely vacuolated cytoplasm suggesting the presence of lipid. Another rare pattern is one in which the granulosa cells are arranged in nodules and are luteinized with variably sized, round, nongrooved nuclei. The appearance resembles that of a pregnancy luteoma except for the origin from granulosa cells and the larger size of their cells.

The differential is usually with a small granulosa or Sertoli cell tumor. Indeed, it is impossible to exclude the possibility that the proliferations are small tumors or tumorlets, although their common association with pregnancy, microscopic size, multifocality, and confinement to atretic follicles suggest a non-neoplastic hormonal response.

\section{Ectopic Decidua}

A decidual reaction within the ovary is usually a response to the hormonal milieu of pregnancy. ${ }^{64-66}$

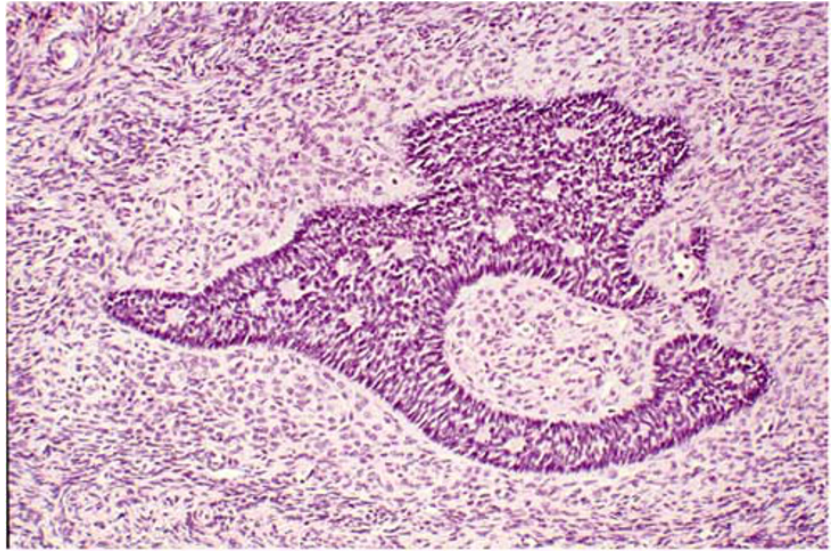

Figure 21 Granulosa cell proliferation pregnancy. The lesion is confined to the centre of an atretic follicle.

It may occur as early as the ninth week of gestation, and is present in almost all ovaries at term. Less commonly, the finding is associated with trophoblastic disease, progestin treatment, an adjacent corpus luteum, a hormonally active ovarian or adrenal lesion, or pelvic irradiation. Occasionally it is an idiopathic finding in a premenopausal or postmenopausal woman.

Ovarian decidua is usually an incidental microscopic finding, but careful inspection may reveal tan to often hemorrhagic, nodules on the ovarian surface and rarely large soft, hemorrhagic masses. The decidua typically occurs within the superficial cortical stroma and within periovarian adhesions, but may be seen within the medulla. The process resembles eutopic decidua and ectopic decidua occurring in other sites, including the occasional presence of cytoplasmic vacuoles that can create a signet-ring-like appearance. The association of these cells with more typical decidual cells, their bland nuclear features, the absence of cytoplasmic neutral mucin, and if necessary, the cytokeratin negativity of the cells, lead to the correct diagnosis.

\section{Other Non-Neoplastic Lesions}

\section{Endometriosis}

Most aspects of this process, in both ovarian and extraovarian sites, are well known and covered in detail in standard texts. ${ }^{67}$ Only a few aspects are considered here. The first is the frequent importance of an association with endometriosis in indicating the nature of various problematic ovarian lesions. For example, the initial interpretation of florid mesothelial hyperplasia within or on the surface of the ovary can be problematic until it is realized that it is secondary to synchronous endometriosis. Similarly, recognition that an adenocarcinoma within the ovary merges with foci of endometriosis can point to a primary rather than a metastatic origin. A second observation in our experience is that small 


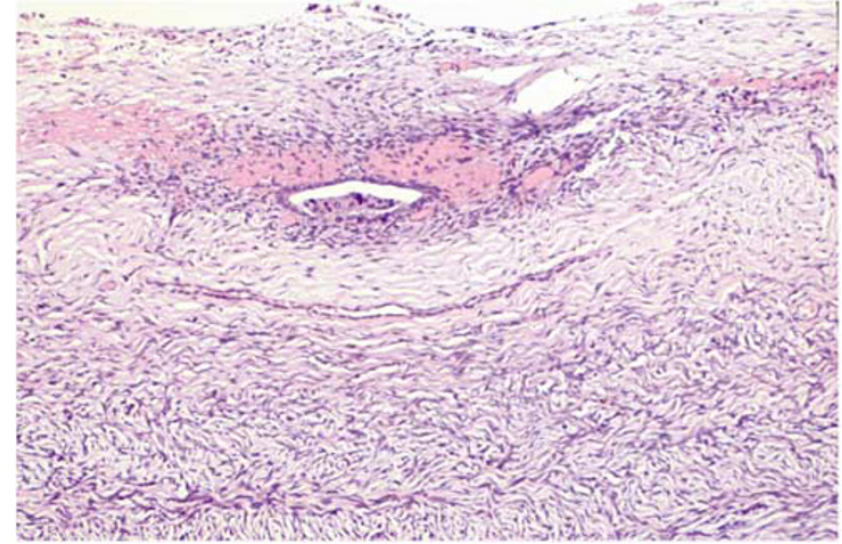

Figure 22 Endometriosis involving ovarian surface. A single endometriotic gland is surrounded by a cuff of endometriotic stroma. The latter is highlighted by the presence of focal hemorrhage.

foci of ovarian endometriosis confined to the ovarian surface can be overlooked (Figure 22). In such cases, the endometriosis takes the form of plaques or small teardrop-shaped projections on the ovarian surface. In these situations, the endometriotic glands and endometriotic stroma can be mistaken for surface epithelial inclusion glands and ovarian stroma, respectively. The presence of small, sometimes dilated, capillaries within the endometriotic stromal component, sometimes associated with hemorrhage, can be a clue to the diagnosis (Figure 22). Immunoreactivity of the stromal cells for CD10 can help confirm their endometriotic nature. ${ }^{68}$

Polypoid endometriosis can occasionally occur in the ovary. In such cases, one or more polypoid tumor-like masses project from the ovarian surface or from the lining of an endometriotic cyst. ${ }^{59}$ Histological examination reveals typical endometriotic glands and stroma, although in some cases the glandular component is hyperplastic. The differential diagnosis in these cases is usually with adenosarcoma, as discussed under the latter heading. Rarely, burned-out foci of ovarian endometriosis can take the form of necrotic granulomatous nodules with numerous foamy and pigmented histiocytes (Figure 23); diagnostic endometriotic glands and stroma are usually absent or sparse. ${ }^{69}$ Occasionally, endometriotic stroma, particularly in the walls of endometriotic cysts, can undergo striking smooth muscle metaplasia ('endomyometriosis'), sometimes with the formation of a uterus-like mass. ${ }^{70,71} \mathrm{Simi}$ larly, the endometriotic stroma can sometimes be extensively replaced by elastosis. ${ }^{72}$

\section{Artifacts and normal findings}

Normal ovarian structures ${ }^{73}$ can occasionally cause concern or be misinterpreted as a neoplasm on microscopic examination. The normal granulosa and theca externa cells are typically mitotically active. This finding in granulosa cells can lead to a

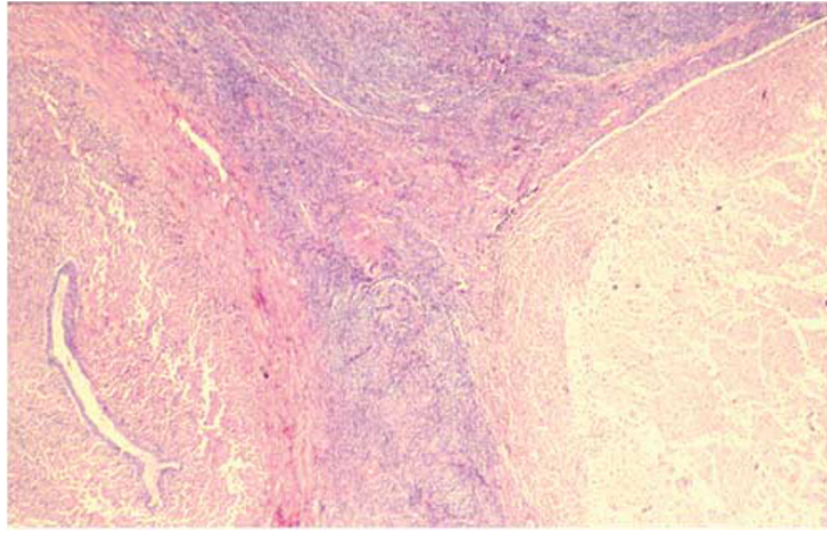

Figure 23 Ovarian endometriosis with the formation of a necrotic pseudoxanthomatous nodule (right). On the left is an endometriotic gland surrounded by numerous foamy histiocytes (pseudoxanthoma cells).

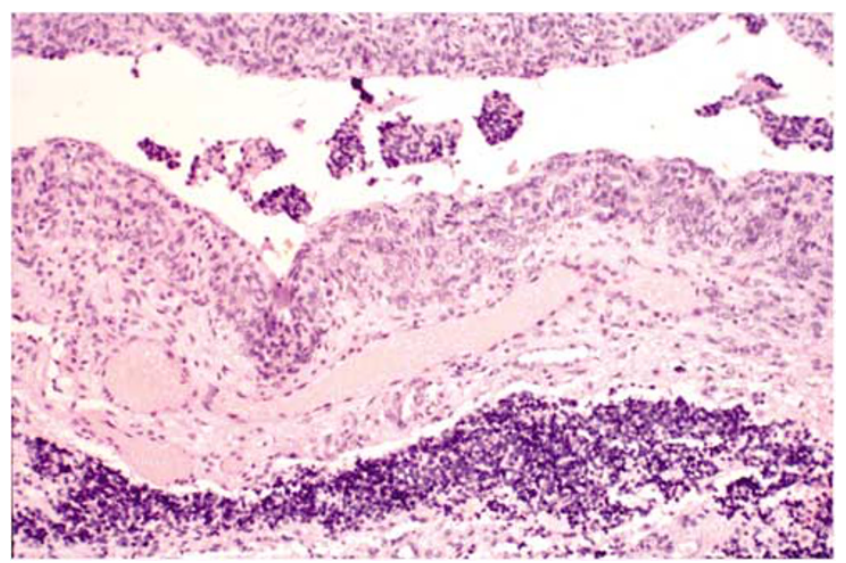

Figure 24 Displaced granulosa cells. Several clusters of detached granulosa cells lie in the cavity of the follicle. A band-like arrangement of similar cells has been artifactually displaced into a cleft in the ovarian stroma (bottom of figure).

misdiagnosis of carcinoma and in theca externa cells a misinterpretation as an small fibrosarcoma, especially if the follicle is cut along its edge and its more central components are absent in the plane of section. Also, the granulosa cells of normal follicles can also be introduced artifactually into tissue spaces (Figure 24) or vascular channels ${ }^{74}$ during sectioning. In such cases, they can be confused with small-cell carcinoma, especially when they are shrunken or crushed (Figure 24). Occasionally, luteinized granulosa cells are present on the surface of the ovary as the result of follicle rupture and may be misinterpreted as mesothelial cells or, if they are numerous, even as malignant mesothelioma. Immunostaining for inhibin can facilitate the diagnosis of granulosa cells in these unusual cases.

\section{Ovarian 'tumor' of the adrenogenital syndrome}

Although this lesion has been well described in the testis, only one example has been reported in the 
ovary. ${ }^{75}$ A 36-year-old woman with congenital adrenal hyperplasia from 21-hydroxylase deficiency experienced an abrupt aggravation of her virilizing symptoms and underwent an adrenalectomy and partial left oophorectomy; persistent virilization led to completion left oophorectomy and right oophorectomy. Each adnexa contained ovarian or paraovarian soft brown masses that were microscopically identical to the testicular 'tumor' of the adrenogenital syndrome.

\section{References}

1 Scully RE. Tumors of the ovary and maldeveloped gonads. Atlas of Tumor Pathology second series, fascicle 16. Armed Forces Institute of Pathology: Washington, DC, 1979.

2 Dickersin GR, Kline IW, Scully RE. Small cell carcinoma of the ovary with hypercalcemia: a report of eleven cases. Cancer 1982;49:188-197.

3 Young RH, Oliva E, Scully RE. Small cell carcinoma of the ovary, hypercalcemic type. A clinicopathologic analysis of 150 cases. Am J Surg Pathol 1994;18:11021116.

4 Scully RE. Small cell carcinoma of hypercalcemic type. Int J Gynecol Pathol 1993;12:148-152.

5 Longy M, Toulouse C, Mage P, et al. Familial cluster of ovarian small cell carcinoma: a new Mendelian entity? J Med Genet 1998;33:333-335.

6 Lamovec J, Bracko M, Cerar O. Familial occurrence of small-cell carcinoma of the ovary. Arch Pathol Lab Med 1995;119:523-527.

7 Fleischhacher DS, Young RH. Dysgerminoma of the ovary associated with hypercalcemia. Gynecol Oncol 1994;52:87-90.

8 Matias-Guiu X, Prat J, Young RH, et al. Human parathyroid hormone-related protein in ovarian small cell carcinoma. An immunohistochemical study. Cancer 1994;73:1878-1881.

9 Editorial. PTHrp: endocrine and autocrine regulator of calcium. Lancet 1991;337:146-148.

10 Aguirre P, Thor AD, Scully RE. Ovarian small cell carcinoma: histogenetic considerations based on immunohistochemical and other findings. Am J Clin Pathol 1989;92:140-149.

11 Seidman JD. Small cell carcinoma of the ovary of the hypercalcemic type: p53 protein accumulation and clinicopathologic features. Gynecol Oncol 1995;59: 283-287.

12 Idei Y, Kitazawa S, Fujimori T, et al. Ovarian small cell carcinoma with K-ras mutation: a case report with genetic analysis. Hum Pathol 1996;27:77-79.

13 Abeler V, Kjostad KE, Nesland JM. Small cell carcinoma of the ovary: a report of six cases. Int J Gynecol Pathol 1988;7:315-329.

14 Dickersin GR, Scully RE. Ovarian small cell tumors: an electron microscopic review. Ultrastruct Pathol 1998; 22:199-226.

15 McMahon JT, Hart WR. Ultrastructural analysis of small cell carcinomas of the ovary. Am J Clin Pathol 1988;90:523-529.

16 Eichhorn JH, Bell DA, Young RH, et al. DNA content and proliferative activity in ovarian small cell carcinomas of the hypercalcemic type. Implications for diagnosis, prognosis, and histogenesis. Am J Clin Pathol 1992;98:579-586.

17 Young RH, Scully RE. Differential diagnosis of ovarian tumors based primarily on their patterns and cell types. Semin Diagn Pathol 2001;18:161-235.

18 Tewari K, Brewer C, Cappuccini F, et al. Advancedstage small cell carcinoma of the ovary in pregnancy: long-term survival after surgical debulking and multiagent chemotherapy. Gynecol Oncol 1997;66: 531-534.

19 Benrubi GI, Pitel P, Lammert N. Small cell carcinoma of the ovary with hypercalcemia responsive to sequencing chemotherapy. Southern Med J 1993;86: 247-248.

20 Scully RE, Dickersin GR. Letter. Int J Gynecol Pathol 1989;8:296-297.

21 Eichhorn JH, Young RH, Scully RE. Primary ovarian small cell carcinoma of pulmonary type. A clinicopathologic, immunohistologic and flow cytometric analysis of 11 cases. Am J Surg Pathol 1992;16: 926-938.

22 Brown H, Lane M. Cushing's and malignant carcinoid syndromes from ovarian neoplasm. Arch Intern Med 1965;115:490-494.

23 Koven BJ, Dollinger MR, Nadel MS. Response to actinomycin D of malignant carcinoid arising in an ovarian teratoma. AM J Obstet Gynecol 1968;101: 267-268.

24 Eichhorn JH, Lawrence WD, Young RH, et al. Ovarian neuroendocrine carcinomas of non-small-cell type associated with surface epithelial adenocarcinomas. Int J Gynecol Pathol 1996;15:303-314.

25 Clement PB, Young RH. Florid mesothelial hyperplasia associated with ovarian tumors: a potential source of error in tumor diagnosis and staging. Int J Gynecol Pathol 1993;12:51-58.

26 Kerner H, Gaton E, Czernobilsky B. Unusual ovarian, tubal and pelvic mesothelial inclusions in patients with endometriosis. Histopathology 1981;5:277-283.

27 Gupta A, Bhan AK, Bell DA. Can the implants of serous borderline tumors of the ovary be distinguished from mesothelial proliferations by the use of immunohistochemistry? Abstract. Mod Pathol 2003;16:10A.

28 Young RH, Silva EG, Scully RE. Ovarian and juxtaovarian adenomatoid tumors: a report of six cases. Int J Gynecol Pathol 1991;10:364-371.

29 Hes O, Perez-Montiel DM, Alvarado Cabrero I, et al. Thread-like bridging strands: a morphologic feature present in all adenomatoid tumors. Ann Diagn Pathol 2003;7:273-277.

30 Skinnider B, Young RH. Infarcted adenomatoid tumor: a report of five cases of a facet of a benign neoplasm that may cause diagnostic difficulty. Am J Surg Pathol 2004;28:77-83.

31 Daya D, McCaughey WTE. Well-differentiated papillary mesothelioma of the peritoneum. A clinicopathologic study of 22 cases. Cancer 1990;65:292-296.

32 Goldblum J, Hart WR. Localized and diffuse mesotheliomas of the genital tract and peritoneum in women. A clinicopathologic study of nineteen true mesothelial neoplasms, other than adenomatoid tumors, multicystic mesotheliomas, and localized fibrous tumors. Am J Surg Pathol 1995;19:1124-1137.

33 Baker PM, Clement PB, Young RH. Malignant peritoneal mesotheliomas in women: A study of 75 cases with emphasis on their morphological spectrum and differential diagnosis (submitted). 
34 Clement PB, Young RH, Scully RE. Malignant mesotheliomas presenting as ovarian masses. Am J Surg Pathol 1996;20:1067-1080.

35 Shanks JH, Harris M, Banerjee SS, et al. Mesotheliomas with deciduoid morphology: a morphologic spectrum and a variant not confined to young females. Am J Surg Pathol 2000;24:285-294.

36 Nascimento AG, Keeney GL, Fletcher CDM. Deciduoid peritoneal mesothelioma: an unusual phenotype affecting young females. Am J Surg Pathol 1994;18: 439-445.

37 Kitazawa M, Kaneko H, Toshima M, et al. Malignant peritoneal mesothelioma with massive foamy cells. Codfish roe-like mesothelioma. Acta Pathol Jpn 1984; 34:687-692.

38 Ordonez NG. Role of immunohistochemistry in distinguishing epithelial peritoneal mesotheliomas from peritoneal and ovarian serous carcinomas. Am J Surg Pathol 1998;22:1203-1214.

39 Gerald WL, Miller $\mathrm{HK}$, Battifora $\mathrm{H}$, et al. Intraabdominal desmoplastic small round cell tumor. Am J Surg Pathol 1991;15:499-513.

40 Young RH, Eichhorn JH, Dickersin GR, et al. Ovarian involvement by the intra-abdominal desmoplastic small round cell tumor with divergent differentiation: a report of three cases. Hum Pathol 1991;23:454-464.

41 Cummings OW, Ulbright TM, Young RH, et al. Desmoplastic small round cell tumors of the paratesticular region. A report of six cases. Am J Surg Pathol 1997;21:219-225.

42 Ordonez NG. Desmoplastic small round cell tumor. I: A histopathologic study of 39 cases with emphasis on unusual histologic patterns. Am J Surg Pathol 1998; 2:1303-1313.

43 Ordonez NG. Desmoplastic small round cell tumor. II: An ultrastructural and immunohistochemical study with emphasis on new histochemical markers. Am J Surg Pathol 1998;22:1303-1313.

44 Lae ME, Roche PC, Jin L, et al. Desmoplastic small round cell tumor. A clinicopathologic, immunohistochemical, and molecular study of 32 tumors. Am J Surg Pathol 2002;26:823-835.

45 Argatoff LH, O’Connell JX, Mathers JA, et al. Detection of the EWS/WT1 gene fusion by reverse transcriptasepolymerase chain reaction in the diagnosis of intraabdominal desmoplastic small round cell tumor. Am J Surg Pathol 1996;20:406-412.

46 Ordi J, de Alava E, Torne A, et al. Intraabdominal desmoplastic small round cell tumor with EWS/ERG fusion transcript. Am J Surg Pathol 1998;22:10261032.

47 Hill DA, Pfeifer JD, Marley EF, et al. WT1 staining reliably differentiates desmoplastic small round cell tumor from Ewing sarcoma/primitive neuroectodermal tumor. Am J Clin Pathol 2000;114:345-353.

48 Barnoud R, Sabourin J, Pasquier D, et al. Immunohistochemical expression of WT1 by desmoplastic small round cell tumor. A comparative study with other small round cell tumors. Am J Surg Pathol 2000;24:830-836.

49 Doss BJ, Wanek SM, Jacques SM, et al. Ovarian leiomyomas: clinicopathologic features in fifteen cases. Int J Gynecol Pathol 1999;18:63-68.

50 Matamala MF, Nogales FF, Aneiros J, et al. Leiomyomas of the ovary. Int J Gynecol Pathol 1988;7:190-196.

51 Prayson RA, Hart WR. Primary smooth-muscle tumors of the ovary. A clinicopathologic study of four leiomyomas and two mitotically active leiomyomas. Arch Pathol Lab Med 1992;116:1068-1071.

52 Lerwill MJ, Sung R, Oliva E, et al. Smooth muscle tumors of the ovary. A clinicopathologic study of 54 cases emphasizing prognostic criteria, histologic variants, and differential diagnosis. Am J Surg Pathol (in press).

53 Costa MJ, Morris R, DeRose PB, et al. Histologic and immunohistochemical evidence for considering ovarian myxoma as a variant of the thecoma-fibroma group of ovarian stromal tumors. Arch Pathol Lab Med 1993;117:802-808.

54 Costa MJ, Thomas W, Majmudar B, et al. Ovarian myxoma: ultrastructural and immunohistochemical findings. Ultrastruct Pathol 1992;16:429-438.

55 Eichhorn JH, Scully RE. Ovarian myxoma: clinicopathologic and immunocytologic analysis of five cases and a review of the literature. Int J Gynecol Pathol 1991;10:156-169.

56 Tetu B, Bonenfant J-L. Ovarian myxoma. A study of two cases with long-term follow-up. Am J Clin Pathol 1991;95:340-346.

57 Eichhorn JH, Young RH, Clement PB, et al. Mesodermal (müllerian) adenosarcoma of the ovary: a clinicopathologic analysis of 40 cases and a review of the literature. Am J Surg Pathol 2002;26:1243-1258.

58 Clement PB, Scully RE. Müllerian adenosarcoma of the uterus: a clinicopathologic analysis of 100 cases with a review of the literature. Hum Pathol 1990;21:363-381.

59 Parker RL, Dadmanesh F, Young RH, et al. Polypoid endometriosis: a clinicopathological analysis of 24 cases and a review of the literature. Am J Surg Pathol 2004;28:285-297.

60 Kaku T, Silverberg SG, Major FJ, et al. Adenosarcoma of the uterus: a gynecologic oncology group clinicopathologic study of 31 cases. Int J Gynecol Pathol 1992;11:75-88.

61 Clement PB. Non-neoplastic lesions of the ovary. In: Kurman RJ (ed). Blaustein's Pathology of the Female Genital Tract, 5th edn. Springer Verlag: New York, 2002, pp 675-727.

62 Clement PB, Scully RE. Large solitary luteinized follicle cyst of pregnancy and puerperium. Am J Surg Pathol 1980;4:431-438.

63 Clement PB, Young RH, Scully RE. Ovarian granulosa cell proliferations of pregnancy. A report of nine cases. Hum Pathol 1988;19:657-662.

64 Bersch W, Alexy E, Heuser HP, et al. Ectopic decidua formation in the ovary (so-called deciduoma). Virch Archiv A (Pathol Anat) 1973;360:173-177.

65 Herr JC, Heidger Jr PM, Scott JR, et al. Decidual cells in the human ovary at term. I. Incidence, gross anatomy and ultrastructural features of merocrine secretion. Am J Anat 1978;152:7-28.

66 Ober WB, Grady HG, Schoenbucher AK. Ectopic ovarian decidua without pregnancy. Am J Pathol 1957; 3:199-217.

67 Clement PB. Diseases of the peritoneum. In: Kurman RJ (ed). Blaustein's Pathology of the Female Genital Tract, 5th edn. Springer-Verlag: New York, 2002, pp 729-789.

68 Groisman GM, Meir A. CD10 is helpful in detecting occult or inconspicuous endometrial stromal cells in cases of presumptive endometriosis. Arch Pathol Lab Med 2003;127:1003-1006.

69 Clement PB, Young RH, Scully RE. Necrotic pseudoxanthomatous nodules of the ovary and peritoneum in endometriosis. Am J Surg Pathol 1988;12:390-397. 
70 Fukunaga M. Smooth muscle metaplasia in ovarian endometriosis. Histopathology 2000;36:348-352.

71 Rahilly MA, Al-Nafussi A. Uterus-like mass of the ovary associated with endometrioid carcinoma. Histopathology 1991;18:549-551.

72 Clement PB, Young RH. Two previously unemphasized features of endometriosis: micronodular stromal endometriosis and endometriosis with stromal elastosis. Int J Surg Pathol 2000;8:223-227.
73 Clement PB. Histology of the ovary. In: Sternberg SS (ed). Histology for Pathologists, 2nd edn. LippincottRaven Publishers: Philadelphia, 1997.

74 McCluggage WG, Young RH. Non-neoplastic granulosa cells within ovarian vascular channels: a rare potential diagnostic pitfall. J Clin Pathol 2004;57:151-154.

75 Al-Ahmadie HA, Stanek J, Liu J, et al. Ovarian 'tumor' of the adrenogenital syndrome. The first reported case. Am J Surg Pathol 2001;25:1443-1450. 